\title{
Visceral Leishmaniasis (Kala-azar) in Nepalgunj Medical College
}

\author{
BK S ${ }^{1}$, Bassi $\mathrm{SD}^{2}$, Baral $\mathrm{S}^{3}$, Shah $\mathrm{A}^{4}$, Dhakal $\mathrm{A}^{5}$
}

\begin{abstract}
ABASTRACT
Background: Visceral leishmaniasis (VL) or Kala-azar is a potentially fatal vector-borne (sand fly phlebotomies spp) zoonotic disease caused by a protozoan parasite, Leishmaniadonovani. Kala-azar remains a public health problem in Nepal. The patient presented with a history of high-grade fever, abdominal distension, anemia, and weight loss. The disease is preventable, but various environmental, socioeconomic, health care and health behavior related variables affect its transmission. Objective: Find out the incidence of Kala-azar infection in Nepalgunj medical college. Method:ThisHospital based study.Data was collected from April 2018 to August 2018. Blood sample collected and test rk39 performed in laboratory of Nepalgunj Medical College Kohalpur. Result: Among 75 patients 16 were diagnosed kala-azar, rk39 positive 14 males and 2 females respectively. It is $12 \%$ of total cases. Among 16 cases male are 14 and 2 are females. $85.7 \%$ male and $12.3 \%$ female. Age group between $15-30$ years (31.25\%), 31-45 years (25\%), 46-60 years(18.75\%), 61-75 years (12.5\%), 76-85 years (12.5\%). young people's age group 15-30 years are commonly infected. Conclusion: Visceral leishmaniasis(kala-azar) cases are still major health problem in Nepal. There shouldbe regular surveillance research work to be carried out in both epidemic and non-epidemic districts of the country. Mass public health education, to make the people aware about preventive aspects of the disease is important.
\end{abstract}

\section{Key words: Epidemiology, leishmaniasis, kala-azar, sandfly}

\section{INTRODUCTION}

Nepal borders with Uttar Pradesh and Bihar states of India along the tropical climatic zone that is afflicted by a wide variety of endemic tropical diseases such as Malaria, Kala-azar, and Encephalitis etc. The wet paddy fields, tropical forest, close settlements, free and unrestricted human movement across the bordercontributes to the incidence of these diseases. This paper focuses on the communicable disease Kala-azar (KA); Visceral Leishmaniasis) which threatens almost one quarter of the country's population ${ }^{1}$.

In Nepal, VL is primarily a disease of the poorest of the poor ${ }^{2,3}$. These people usually live in the mud houses having cracked walls and damp floors, which constitute excellent condition for attraction and hiding of sand-fly. Moreover, majority of these people sleep outside of their houses during the summer, without bed nets, which is most favorable situation for the sand-fly to bite and transmit the infection. Although VL cases are still being reported at lower rate in Nepal since 1998 but this might have also been due to out-migration to the Middle-

\footnotetext{
1. Dr. Shyam Kumar B.K.

2. Prof. S.D. Bassi

3. Dr. S. Baral

4. Dr. A. Shah

5. Dr. A. Dhakal
}

Address for correspondence:

Dr. Shyam Kumar. B.K.

Department of Medicine

Nepalgunj Medical College \& Teaching Hospital

Kohalpur, Banke

Email:dr.shyamyp@gmail.com
East counties for employment and carry back infection into Nepal $^{4,5}$.

In Nepal, VL primarily manifests as fever, anaemia, hepato and splenomegaly, resulting in death if it is untreated. The diagnosis of VL in Nepal is largely based on clinical signs and symptoms, usually combined with positive formal-gel test ${ }^{6}$. At present, the most widely used immunological tests to detect VL in Nepal are the nitrocellulose dipstick test that detects antibody to the recombinant amastigote antigen $\mathrm{K} 39$ (rK39), direct agglutination test, and latex agglutination test ${ }^{7}$.

His Majesty's Government of Nepal (HMG/N) has acknowledged the necessity of maintaining a healthy population as a means of poverty alleviation and in this regard, it has initiated measures for the control of KA and abatement of its disastrous effects on the households since the first KA case was identified in the country in $1980^{\circ}$. Furthermore, it has been felt that simply addressing the disease from and epidemiological level has been insufficient, and that effective programs should take into account both the socio-economic and behavioral factors of the KA susceptible household ${ }^{9}$.

VL cases may be underestimated in these regions. Treatment failure with pentavalent antimonial (sodium stibogluconate [SSG]) has been reported in the recent years in Nepal and as a result, a single dose liposomal Amphotericin B is currently. recommended by National Program of Nepal for kala-azar treatment. Not only is the emergence and spread of drug resistance troubling, but VL cases have been recently reported from the regions that were previously considered to be nonendemic in Nepal. 


\section{MATERIAL AND METHODS}

This is a hospital based cross sectional study done in Nepalgunj Medical College Teaching Hospital Kohalpur. Data was collected from April 2018 to August 2018. Those patients who are admitted in medical wards with signs and symptoms of Kala-azar, having fever, anemia more than month. Sample was collected from 15 years to 85 years of patients. Collected blood sample was tested in laboratory of Nepalgunj Medical College Kohalpur. Rapid dipstick (rk39 test) was performed in lab. Data is analyzed by SPSS 20 version.

Among the available serological diagnosis of $V L$, only the immunochromatographic rK39 assay can be considered a point of care test for field application. On the Indian subcontinent these rK39 RDTs from different companies performed well, with high sensitivity ranging from $92.8 \%$ to $100 \%$ and high specificity ranging from $99.2 \%$ to $100 \%$ (Chappuius et al., 2006; Cunningham et al. 2012). rK39 dipstick tests are easy to perfos.

\section{RESULTS}

Among suspected cases of 75, 59 are found negative and 16 cases found infected from Kala-azar (rk39 test positive). It accounts $12 \%$ of total cases.

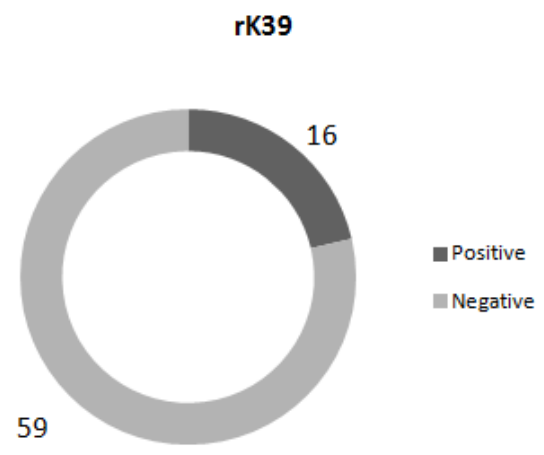

Figure 1:

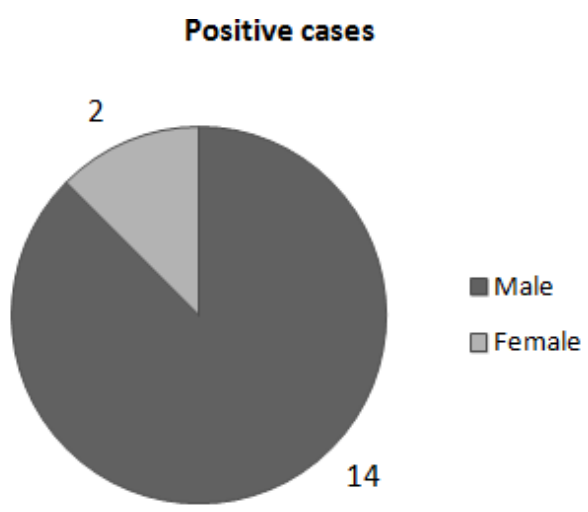

Figure 2: Sex distribution

Among 16 cases male are 14 and Female 2. 85.7\% male and $12.3 \%$ female. Males are more affected than females.

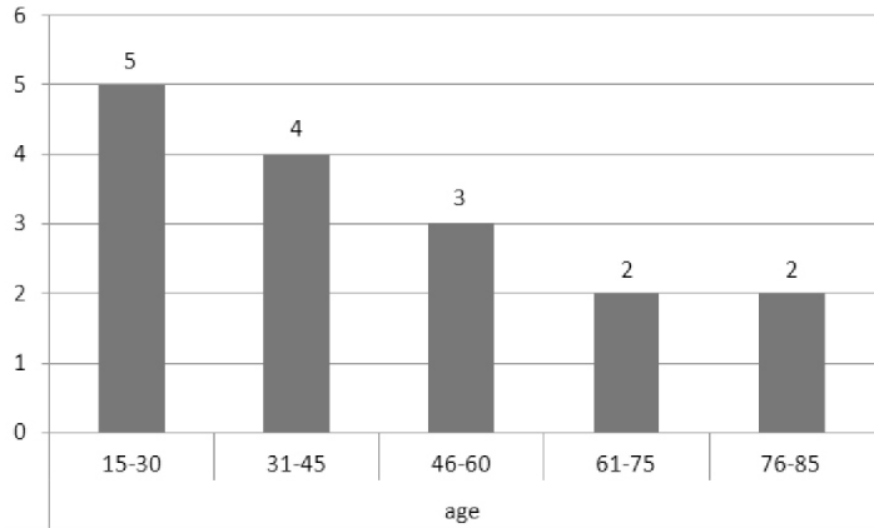

Figure 3: Age distribution

In this study young peoples are commonly affected then elderly. Age group between $15-30$ years (31.25\%), 31-45 years (25\%), $46-60$ years (18.75\%), 61-75 years(12.5\%), $76-85$ years (12.5\%). young people's age group $15-30$ years are commonly infected.

\section{DISCUSSION}

Visceral leishmaniasis $(\mathrm{VL})$ is still posing a major public health threat in terai belt of Nepal, but decreasing in trends since last few years. In my study among suspected cases of 75, 59 are found negative and 16 cases found infected from Kala-azar (rk39 test positive). It accounts $12 \%$ of total cases.

Prevalence of visceral leishmaniasis in Saptari district during last five years showed the declining trend of VL cases from the year 2007 to 2012 . Highest prevalence was recorded in the year 2007 with prevalence of $31.5 \%$ VL cases in Saptari district, which is reduced by $3.5 \%$ in $2012^{10}$. Of the total eighteen suspected patients with Kala-azar were tested by aldehyde and bone-marrow methods. Among them, 33.33\% (6/18) were positive for aldehyde test only and $83.3 \%$ (5/6) for bonemarrow in terai region of Nepal. ${ }^{11}$

In my study among 16 cases male are 14 and 2 are females. $85.7 \%$ male and $12.3 \%$ female. Males are more affected than females. The CFR in male was 13\% and 11\% during 1996 and 1997 and in female it was $8 \%$ and $13 \%$ respectively ${ }^{12}$. The identified $\mathrm{KA} \mathrm{HH}$ had a total population of 451 with 243 male and 208 females, $53.8 \%$ male and $46.1 \%$ females, Sharma BP et $\mathrm{al}^{13}$. In contrast to another study of Bihar where majority $(97.0 \%)$ of the respondents were males ${ }^{14}$ in the current study majority $(50.5 \%)$ of the respondents were female, however it is supported by the study conducted in South Gondar where majority of the respondents were female $60.7 \%{ }^{15}$.

In our study young peoples are commonly affected then elderly. Age group between $15-30$ years (31.25\%), 31-45 years (25\%), $46-60$ years (18.75\%), 61-75 years (12.5\%), $76-85$ years (12.5\%). Young people's age group $15-30$ years are commonly infected. 
In the study, majority (35.2\%) of the respondents were 21-30 years age, which is consistent with the findings of study of Bihar where $26.7 \%$ were between $25-34$ years ${ }^{16}$. Similar to the work by Ranjan and others, those individuals 21 years and older accounted for the highest percentage of cases $(42 \%)$, whereas the current study also had $40 \%$ of the total cases in children ages $0-10$ years ${ }^{17}$.

\section{CONCLUSION}

Visceral leishmaniasis( Kala-azar) first appeared in the Eastern terai parts of Nepal during 1982. Due to proper vector control and effective treatment incidence of Kala-azar decreasing since last few years. But due to lack of easy drug availability cases of kala-azar can be seen in many parts of Nepal most commonly terai region of Nepal. Regular epidemiological surveillance in all terai districts is warranted in view of migration of Kala-azar cases from endemic districts coupled with the presence of high vector density, animal reservoirs ambient environmental and ecological factors, susceptible population and absence of regular insecticidal spraying in Nepal by the concerned institutions.

\section{REFRENCES}

1. Bista MB, Vaidya RG, Thakur GD and Pokharel RK. The annual internal assessment of malaria andKala-azar control activities. Kathmandu, 2002.Department of Health Services, Epidemiology andDisease Control Division, Ministry of Health, His Majesty's Government of Nepal 2004.

2. Gratz NG. Emerging and resurging vector-borne diseases.Ann Rev Entomol1999; 44:51-57.

3. Chelala C. The poor man's disease.In: HimalSouthasian. 2004.

4. Parija SC, Jacob M, Karki BMS, Manoj S, Karki P, Koirala S. Cutaneous Leishmaniasis in Nepal.Southeast Asian J Trop Med Pub Health 1998;1:29.

5. Desjeux P. Leishmaniasis: Current Situation and New Perspectives. ComparlmmunolMicrobiol \& Infect Dis 2004;27:305-18.

6. Rijal S, Chappuis F, Singh R, Bovier PA, Acharya P, Karki BMS, Das $M L$, Desjeux P, Loutan $L$ and Koirala S. Treatment of Visceral Leishmaniasis in South-Eastern Nepal: Decreasing Efficacy of Sodium Stibogluconate and Need for a Policy to Limit Further Decline. Trans Royal Soc Trop MedHyg2003;97:350-4.

7. Bern C, Jha SN, Joshi AB, Thakur GD and Bista MB. Use of the Recombinant K39 Dipstick Test and the Direct Agglutination Test in a Setting Endemic for Visceral Leishmaniasis in Nepal. AmJ Trop Med Hyg2000;63:153-57.

8. Chelala C. The poor man's disease: The history and the present reality of a dastardly disease that hits the poorest in the poorest regions of South-Asia. Himal South Asian 2004.

9. Wijeyaratne, PM, LK Jones Arsenault and CJ Murphy. Endemic disease and development: the Leishmaniasis. Acta Tropica 1994; 56:349-64.

10. Bern, C, Hightower AW, Chowdhury, R., Ali, M. and Amann. J. 2005. Risk factors for kala-azar in Bangladesh. Emerging Infectious Disease.11: 655-662.

11. Desjeux P. Leishmaniasis: Current Situation and New Perspectives. ComparlmmunolMicrobiol \& Infect Dis 2004;27:305-18.
12. Devkota UN. Descriptive Epidemiology of Visceral Leishmaniasis in Nepal 1993.J Nepal Med Assoc1993;31:329-326.

13. Sharma BP, Maskay NM and Adhikari SR. Kalaazar policy and plans in Nepal: evaluation and assessment. working paper 2005.

14. Singh SP, Reddy DC, Mishra RN, Sundar S. Knowledge, attitude and practices related to Kala-azar in a rural area of Bihar state, India. The American Journal Of Tropical Medicine and Hygiene. 2006;75(3);505-8.

15. Alemu A, Abebe A, Esmael N, Dessie Y, Mathews K, Binlam M, Birhan W. Knowledge, attitude and practices related to visceral leishmaniasis among residents in Addis Zemen town. South Gondar Northwest Ethiopia. Bio Medical Centre of Public Health. 2013;13:382.

16. Siddhique NA, Kumar N, Ranja A, Das VN, Pandey K, Verma RB, Das P. Awareness about Kala-azar disease and related preventive attitudes and practices in a highly endemic rural area of India. Asian Journal Tropical Medical Public Health. 2010;41(1);1-12.

17. Ranjan A, Sur D, Singh VP, Siddigue NA, Manna B, Lal CS, Sinha PK, Kishore K, Bhattacharya SK. Risk factors for Indian Kala-azar. Am J Trop Med Hyg. 2005;73:74-78. 